Supplementary Information

\title{
The Role of Stirring and Amino Acid Mixtures to Surpass the Sluggishness of $\mathrm{CO}_{2}$ Hydrates
}

\author{
Tulluru Bhavya a , Burla Sai Kiran ${ }^{\mathrm{a}, \mathrm{b}}$ and Pinnelli S R Prasad ${ }^{*}$, a,b
}

${ }^{a}$ Gas Hydrate Division, CSIR-National Geophysical Research Institute (CSIR-NGRI) HYDERABAD - 500007 (India)

${ }^{b}$ Academy of Scientific and Innovative Research (AcSIR), Ghaziabad- 201002, India Corresponding author's e-mail: psrprasad@ngri.res.in; Phone: +91 402701 2710;

Fax: +914027171564

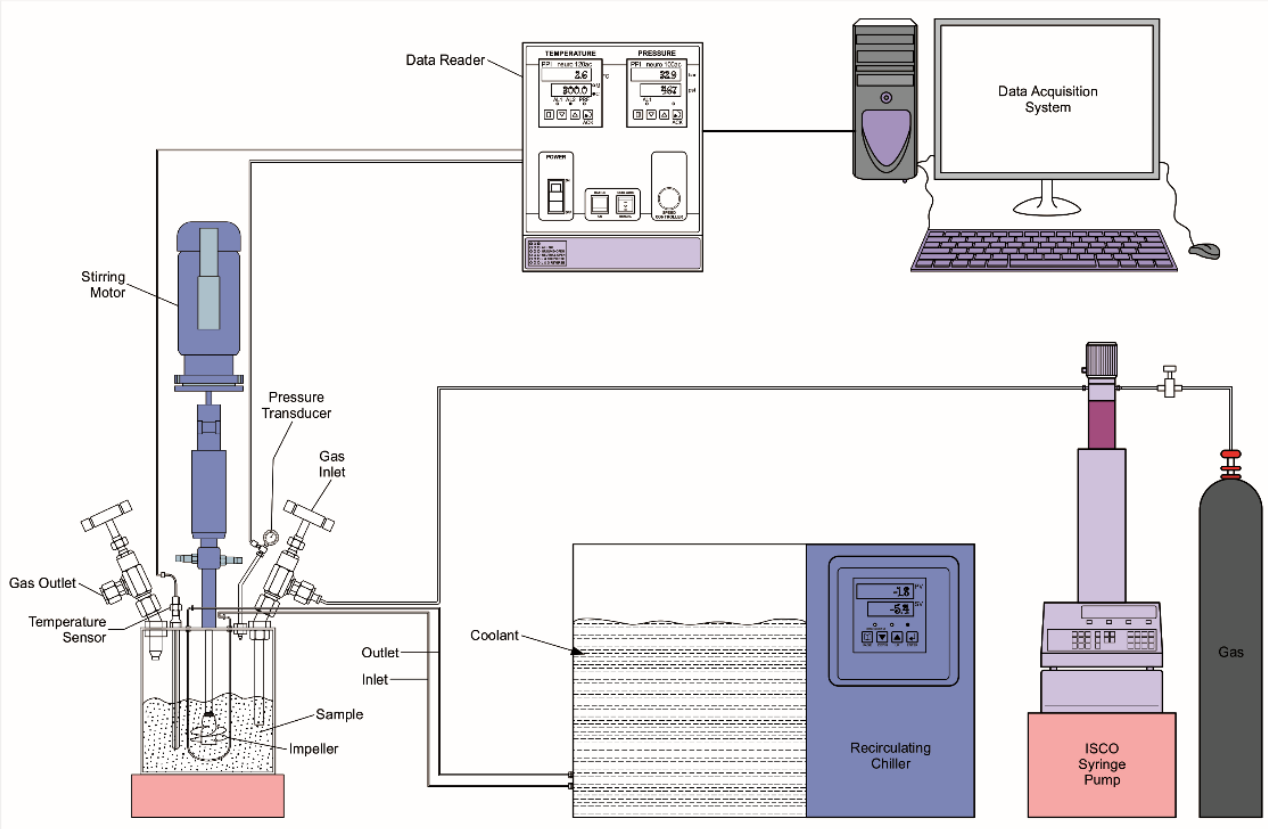

Figure S1: The schematic experimental design used for the hydrate synthesis. 

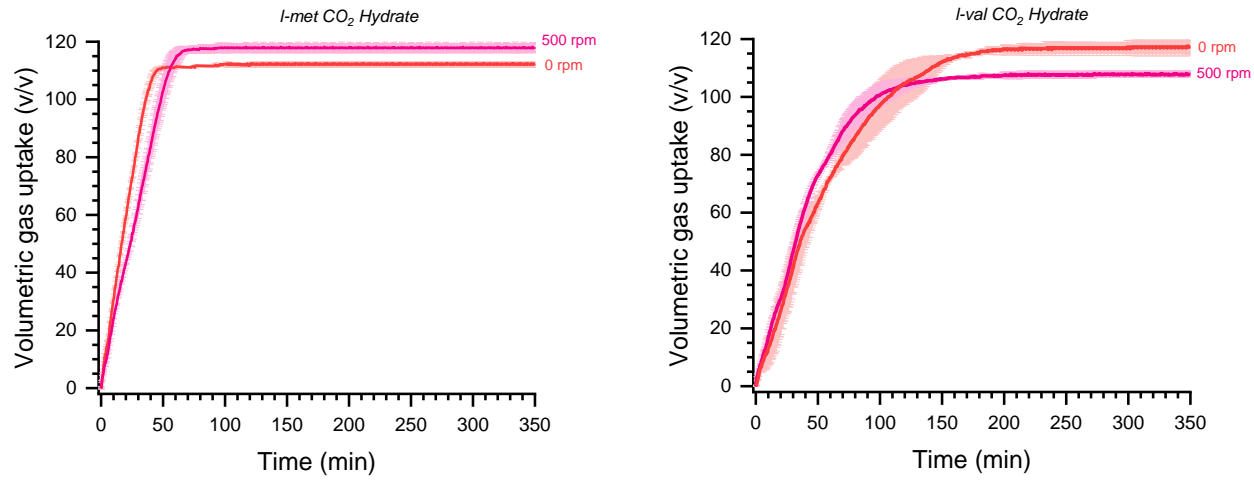

Figure S2: The carbon dioxide hydrate formation with a) I-met and b) I-val systems. 